\title{
Syntheses with Azido-sugars ${ }^{\dagger}$
}

\section{Part II. Conversion of D-Glucose to (+)-Desthiobiotin ${ }^{\text {t十 }}$}

\author{
By Hiroyoshi Kuzuhara, Hiroshi Ohrui and Sakae Emoto
}

\author{
The Institute of Physical and Chemical Research \\ Yamato-machi, Kita-adachi-gun, Saitama-ken
}

Received May 23, 1970

\begin{abstract}
(+)-Desthiobiotin (IIa) was prepared from D-glucose via several derivatives of azidosugars. The fourth and the fifth carbons of $\mathrm{D}$-glucose were changed into two asymmetric carbons of Ila through the reaction.
\end{abstract}

Although many asymmetric carbons exist in a carbohydrate molecule, few of them have been utilized for the preparation of optically active compounds. From this view-point, we planned to prepare two compounds related to $(+)$-biotin from some carbohydrate derivatives. One was (+)-oxybiotin and its synthesis from D-glucose was already achieved." This paper deals with the preparation of the other compound, (+)-desthiobiotin, from D-glucose.

$(+)$-Desthiobiotin was first prepared as its methyl ester by removal of sulfur from (+)biotin methyl ester (Ib) with Raney nickel in the course of the structural elucidation of $(+)-$ biotin ( $(\mathrm{Ia})^{21}$ and was later found to be biologically as active as Ia for some microorganisms."

+ The paper cited in footnote 1 is regarded as consisting Part I of this series.

t† Presented at the Annual Meeting of the Agricultural Chemical Society of Japan, Fukuoka, April 1970; Preliminary communicated. H. Kuzuhara, H. Ohrui and S. Emoto, Tetrahedron Letters, 1970, 1185.

1) Presented at the Annual Meeting of the Agricultural Chemical Society of Japan, Tokyo, April 1969. Published in part, H. Ohrui, H. Kuzuhara and S. Emoto, Agr. Biol. Chem., 34, 375 (1970).

2) V. du Vigneaud, D. B. Melville, K. Folkers, D. E. Wolf, R. Mozingo, J. C. Keresztesy and S. A. Harris, J. Biol. Chem., 146, 475 (1942).

3) S.F. Dyke, "The Chemistry of Natural Products," Vol. 6, Interscience Publishers (London), 1965, pp. 176; L. H. Sternback "Comprehensive Biochemistry," Vol. 11, Elsevier Publishing Co. (Amsterdam), 1963, pp. 74.

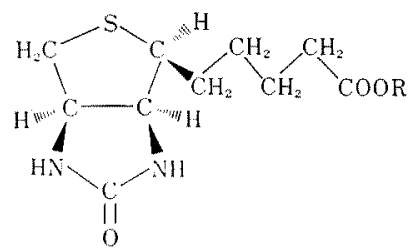

(Ia) $\mathrm{R}=\mathrm{H}$

(Ib) $\mathrm{R}=\mathrm{CH}_{3}$<smiles>[R]OC(=O)CCCCC[C@@H]1CNC(=O)N1</smiles>

FIG. 1.

The preparation of (+)-desthiobiotin from other sources has never been reported although the racemic compound was synthesized by three groups." Absolute configuration of Ia was recently proposed by Trotter and Hamilton on the basis of the result of X-ray analysis (anomalous diffraction) of a $(+)$-biotin de-

4) J. L. Wood and V. du Vigneaud, J.Am. Chem. Soc., 67, 210 (1945); J. P. Bourquin, O. Schnider and A. Grussner, Helv. Chim. Acta, 28, 528 (1945); R. Duschinsky and L. A. Dolan, J. Am. Chem. Soc., 67, 2079 (1945). 

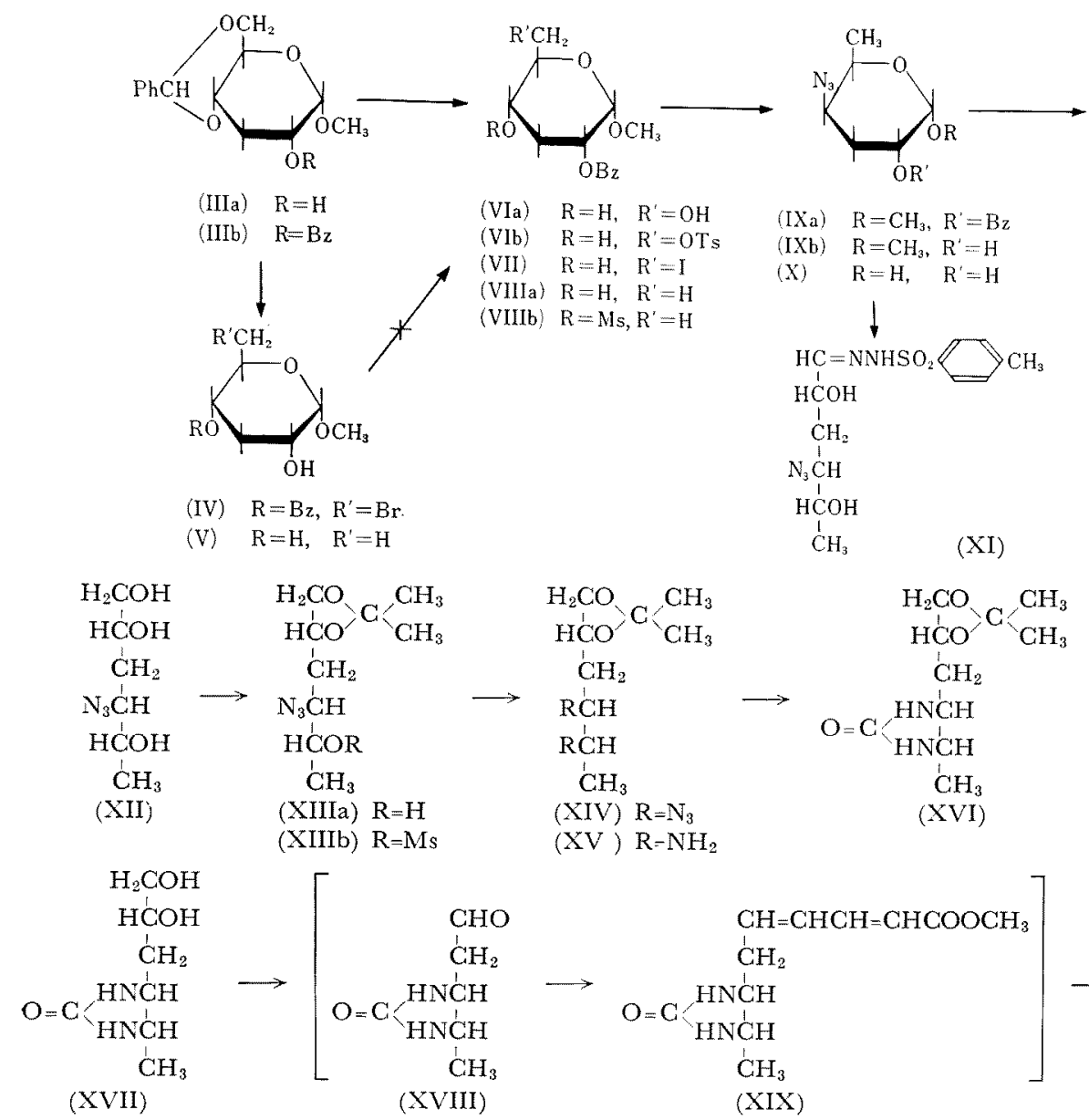

$(\mathrm{ph})_{3}-\mathrm{P}=\mathrm{CH}-\mathrm{CH}=\mathrm{CHCOOCH}$

(XX)

Bz=-Benzoyl

Ms=Methylsulfonyl

$\mathrm{Ph}=\mathrm{Phenyl}$

Ts $=p$-Tolylsulfonyl

FIG. 2 .

rivative. ${ }^{51}$ Consequently, the absolute configuration of (+)-desthiobiotin may be justifiably assigned as shown in IIa if it is assumed that desulfurization of Ib does not cause configurational changes of the amino groups. In order to ascertain this point and determine

5) J. Trotter and J. A. Hamilton, Biochem., 5, 713 (1966). the absolute configuration of (+)-desthiobiotin, it will be significant to prepare the compound having the structure IIa from a compound with a well established configuration.

The preparation of two amino groups on contiguous carbons in erythro orientation is a key point in the synthesis of IIa. This was conducted by introducing two azide groups into a sugar intermediate in such an orientation 
TABle I. NMR PARAMETers ${ }^{23)}$ FOR COMPOUNDS, VIIIb and IXa

\begin{tabular}{|c|c|c|c|c|c|c|c|}
\hline \multirow{2}{*}{ Compounds } & & \multicolumn{6}{|c|}{ Protons } \\
\hline & & $\mathrm{H}-1$ & $\mathrm{H}-2$ & $\mathrm{H}-3$ & $\mathrm{H}-4$ & $H-5$ & $\mathrm{H}-6$ \\
\hline \multirow{4}{*}{ VIIIb } & Chemical shift $(\tau)$ & \multicolumn{2}{|c|}{$4.65 \sim 5.20$} & $7.30 \sim 7.75$ & 5.57 & 6.18 & 8.66 \\
\hline & Number of protons & \multicolumn{2}{|c|}{2} & 2 & 1 & 1 & 3 \\
\hline & Splitting & \multicolumn{2}{|c|}{ multiplet } & multiplet & multiplet & octet $^{a 1}$ & doublet \\
\hline & $\begin{array}{l}\text { Coupling constant } \\
(\mathrm{Hz})\end{array}$ & & & & & $\begin{array}{l}J_{4,5}=10.2 \\
J_{5,6}=6.0\end{array}$ & $J_{5,6}=6.0$ \\
\hline \multirow{6}{*}{$\mathrm{Ma}$} & Chemical shift $(\tau)$ & 5.05 & 4.73 & $7.50 \sim 7.82$ & 6.26 & 5.90 & 8.70 \\
\hline & Number of protons & 1 & 1 & 2 & 1 & 1 & 3 \\
\hline & Splitting & doublet & octet & multiplet & multiplet & octet $^{b 1}$ & doublet \\
\hline & Coupling constant & $J_{1,2}=3.6$ & $J_{1,2}=3.6$ & & & $J_{4,5}=1.8$ & $J_{5,6}=6.6$ \\
\hline & $(\mathrm{Hz})$ & & $J_{2,3 e}=7.2$ & & & $J_{5,6}=6.6$ & \\
\hline & & & $J_{2,3 \mathrm{a}}=13.2$ & & & & \\
\hline
\end{tabular}

a) This collapsed to a doublet on irradiation at $\tau 8.66$.

$b$ : This collapsed to a doublet on irradiation at $\tau 8.70$.

and by reducing them subsequently.

Methyl 4,6-O-benzylidene-3-deoxy- $\alpha$-D-ribohexopyranoside (IIIa) had been prepared from D-glucose by Vis and $\mathrm{Karrer}^{6)}$ and employed as a starting material for the preparation of IIa.

Two schemes were undertaken to synthesize methyl 2-O-benzoyl-3,6-dideoxy- $\alpha$-D-ribo-hexopyranoside (VIIIa) which was one of the important intermediates for the preparation of IIa. In the first attempt, IIIa was treated with N-bromosuccinimide, giving syrupy methyl 4-O-benzoyl-6-bromo-3, 6-dideoxy- $\alpha$-Dribo-hexopyranoside (IV). ${ }^{71}$ Compound IV was reduced catalytically with Raney nickel in the presence of potassium hydroxide to afford methyl 3,6-dideoxy- $\alpha$-D-ribo-hexopyranoside (V). An attempt to get VIIIa by partial benzoylation of $V$ was not successful although a hydrogen bond was expected to exist in the molecule of $\mathrm{V}$ between the hydroxyl group at C-2 and the oxygen atom of

6) E. Vis and P. Karrer, Helv. Chim. Acta, 37, 378 (1954).

7) The identification of this compound was based on the result described in the literature shown below: S. Hannessian and N. P. Plessas, J. Org. Chem., 34, 1035 (1969) the methoxy group at $\mathrm{C}-1 .^{81}$ Therefore, an alternative pathway, a more conventional one, was adopted to prepare VIIIa. Compound III a was benzoylated to methyl 2-O-benzoyl4, 6-O-benzylidene-3-deoxy- $\alpha$-D-ribo-hexopyranoside (IIIb) and the benzylidene group of IIIb was removed by acid in $p$-dioxane, ${ }^{91}$ giving methyl 2-O-benzoyl-3-deoxy- $\alpha$-D-ribo-hexopyranoside (VIa). Partial tosylation of VIa afforded 6-tosylate (VIb) which was treated with sodium iodide in 2-butanone under reflux. The resulting methyl 2-O-benzoyl-3,6-dideoxy6 -iodo- $\alpha$-D-ribo-hexopyranoside (VII) was reduced catalytically in the presence of sodium acetate to give VIIIa. The over-all yield of VIIIa was $45 \%$ from IIIa.

Compound VIIIa was then methylsulfonylated in the usual manner to give 4-mesylate (VIIIb). The methylsulfonyloxy group of VIIIb was replaced with an azide group by treatment of VIIIb with sodium azide in $\mathrm{N}$, $\mathrm{N}$-dimethylformamide (DMF) and methyl 4-

8) Generally a hydroxyl group forming a hydrogen bond is more easily acylated than non-bonded one. For example, see Coll. Czeck. Chem. Comm., 35, $321(1970)$.

9) H. Kuzuhara, H. Ohrui and S. Emoto, Carbohydrate Research, 11, 9 (1969). 
azido-2-O-benzoyl-3,4,6-trideoxy- $\alpha$-D- $x y l o$-hexopyranoside (IXa) was obtained in $930 \%$ yield. This substitution accompanied a configurational inversion at $\mathrm{C}-4$ as a result of the $\mathrm{S}_{\mathrm{N}} 2$ type of replacement, ${ }^{10)}$ which was proved by comparing the NMR spectrum of IXa with that of VIIIb (Table I). Although the splittings of $\mathrm{H}-4$ signals were not well resolved in the both spectra, H-5 signals which were assigned by double resonance with methyl protons at C-6 were well analysed. The change of $J_{4,5}$ value $(10.2 \mathrm{~Hz} \rightarrow 1.8 \mathrm{~Hz})$ during the substitution reaction shows that the relative configuration of $\mathrm{H}-4$ and $\mathrm{H}-5$ changes from axial-axial to equatorial-axial.

In connection with the configurational and the conformational analyses of IXa, it is interesting to measure the circular dichroism (CD) of this type of compounds since the sign of the cotton effect of 4-azido-hexose cannot be predicted from the "azide octant rule",11) which was recently extended to the field of sugar studies. ${ }^{121}$ After the benzoyl group which might interfere the cotton effect due to the azide group was removed from IXa with a base, the CD curve of the resulting methyl 4 -azido-3,4,6-trideoxy- $\alpha$-D- $x y$ lo-hexopyranoside (IXb) was observed and found to have a positive cotton effect $\left([\theta]_{286}+188\right)$.

The next step towards IIa was hydrolysis of the glycosidic linkage of IXa. Thus, acetolysis of IXa gave an anomeric mixture of 1-acetate and subsequent hydrolysis of the mixture with a base afforded a sole product, crystalline 4-azido-3,4,6-trideoxy- $\alpha$-D- $x y$ lo-hexopyranose $(\mathrm{X})$. The anomeric configuration of $\mathrm{X}$ was determined by measuring mutarotation, $[\alpha]_{D}-15^{\circ} \rightarrow-43^{\circ}\left(\mathrm{H}_{2} \mathrm{O}\right)$ and NMR spectrum in dimethylsulfoxide- $\mathrm{d}_{6}{ }^{13 !}\left(\mathrm{H}-1, \tau 5.12, J_{1,2}=\right.$

10) In this case there is no factor which inhibits a simple $\mathrm{S}_{\mathrm{N}} 2$ substitution. See, A. C. Richardson, Carbohydrate Research, 10, 395 (1969).

11) C. Djerassi, A. Moscowitz, K. Ponsold and G. Steiner, J. Am. Chem. Soc., 89, 347 (1967).

12) H. Paulsen, Chem. Ber., 101, I571 (1968).
$3.6 \mathrm{~Hz}$ ). For further identification of $\mathrm{X}$ its $p$-tolylsulfonylhydrazone (XI) was prepared.

When $\mathrm{X}$ was treated with sodium borohydride at $0^{\circ} \mathrm{G}$ for $30 \mathrm{~min}$, only hemiacetal was reduced leaving the azide group unaffected and syrupy 4-azido-3,4,6-trideoxy-D-xylo-hexitol (XII) was obtained in more than $90 \% \%$ yield. For protecting the hydroxyl groups at $\mathrm{C}-1$ and C-2 XII was condensed with acetone in the presence of acidic ion-exchange resin to afford 4-azido-1, 2-O-isopropylidene-3, 4, 6-trideoxy-D$x y l o$-hexitol (XIIIa). The second azide group was introduced to the carbohydrate intermediate in the same way as for the first one. Thus, XIIIa was methylsulfonylated and the resulting 4-methylsulfonate (XIIIb) was treated with sodium azide in DMF to yield a syrupy compound which has two azide groups. The diazido-compound may reasonably be assigned to be 4,5-diazido-1,2-O-isopropylidene-3,4,5,6tetradeoxy-L-arabino-hexitol (XIV), since the azide group at $\mathrm{C}-4$ does not participate in the substitution at $\mathrm{C}-5 .^{141}$

Catalytic reduction of the azide groups of XIV with Adams platinum was found to proceed incompletely. ${ }^{15)}$ When Raney nickel was used under a slightly high pressure (ca. $4 \mathrm{~kg}$ ) $\mathrm{cm}^{2}$ ) of hydrogen, however, XIV was reduced smoothly to yield the corresponding diamine $(\mathrm{XV})$. Without further purification $\mathrm{XV}$ was treated with carbonyl chloride in water in the presence of sodium carbonate to give crystalline 4, 5-N-carbonyl-4, 5-diamino-1, 2-Oisopropylidene-3,4,5,6-tetradeoxy-L-arabino-hexitol (XVI) in 33\% yield from XIV. The isopropylidene group of XVI was removed with an acidic ion-exchange resin in water at

13) The conformation and the anomeric configuration of a sugar do not change in dimethylsulfoxide. See B. Casu, M. Reggiani, G. G. Gallo and A. Vigevani, Tetrahedron Letters, 1964, 2839.

14) L. Goodman, "Advances in Carbohydrate Chemistry," Vol. 22, Academic Press, 1967, pp. 154.

15) After XIV was shaken for $5 \mathrm{hr}$ in hydrogen which was replaced several times with fresh hydrogen, the product still showed an absorption at 2100 $\mathrm{cm}^{-1}$ in IR spectrum for the azido group. 
room temperature and crystalline $4,5-\mathrm{N}$-carbonyl-4, 5-diamino-3,4,5,6-tetradeoxy-L-arabino-hexitol (XVII) was obtained in $86 \%$ yield.

The next three steps of the reactions (periodate oxidation, Wittig reaction, and catalytic hydrogenation) were carried out continuously without characterization of the products because of their quantitative limitation and instability. Compound XVII was cleaved with periodate in water between C-1 and C-2 and the resulting aldehyde (XVIII) was extracted with absolute ethanol after careful concentration by freeze-drying. Judging from the results of periodate oxidation in other sugar studies, ${ }^{16)}$ XVIII probably forms a dimer or an adduct with formaldehyde (by-product of the oxidation) in such a way that the aldehyde group was masked.

On the other hand, several Wittig reactions were recently reported to be successful with

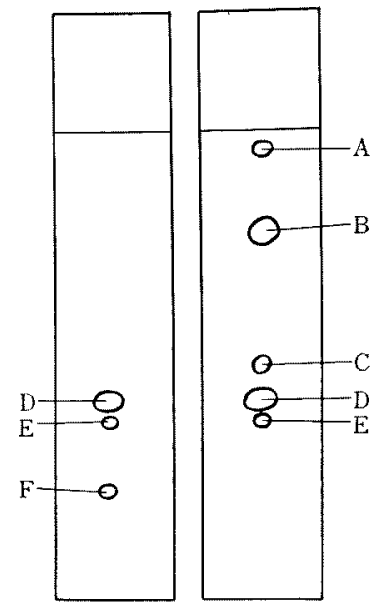

FIG. 3. Thin-layer Chromatogram ${ }^{19)}$ of the Products of the Wittig Reaction Detected in Two Ways. Right, under UV-light; Left, with a reagent. ${ }^{201}$

Chloroform-methanol $(94: 6 \mathrm{v} / \mathrm{v})$ was used as a developer.

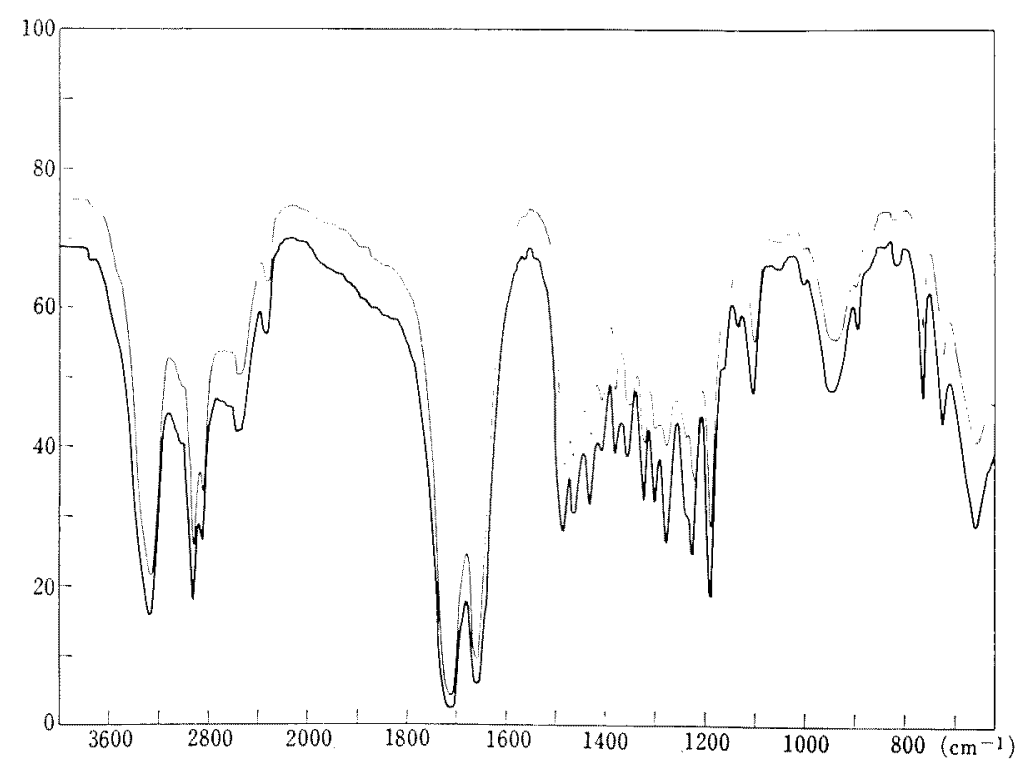

FIG. 4. IR Spectra of the Prepared (+)-Desthiobiotin and of the Authentic One. (KBr) - From D-glucose; —, From $(+)$-biotin.

16) For example, see T. D. Inch, Carbohydrate Research, 5, 53 (1967). 
a masked aldehyde such as hemiacetal. ${ }^{171}$ Therefore, two equivalents of the Wittig reagent, [3-carbomethoxy-propen-(2)-yliden-(1)]triphenylphosphorane (XX), ${ }^{18)}$ was added to the alcoholic extract of XVIII and the mixture was kept at room temperature for two days. Five products $(A \sim E)$ were detected on thinlayer chromatogram ${ }^{191}$ of the reaction mixture under UV light (Right side of Fig. 3), and three products $(D \sim F)$ were detected when a t.l.c. plate was sprayed with the reagent ${ }^{201}$ and charred (Left side of Fig. 3). Either D or $\mathrm{E}^{21)}$ should be methyl 7,8-N-carbonyl-7(R), 8(S)-diamino-nona-2,4-dienoate (XIX) because XIX having a conjugate system and an acidlabile ureide was to be detected by the both methods. Therefore, $\mathrm{D}$ and $\mathrm{E}^{221}$ (approximate ratio, $3: 1$ ) was respectively isolated by column chromatography and subsequent preparative layer chromatography, although the separated $\mathrm{E}$ was not pure enough for further studies. The major product $\mathrm{D}$ was hydrogenated with Adams catalyst and the resulting syrup was purified by high vacuum distillation and subsequent column chromatography to give a

17) H. J. Bestman and J. Angerer, Tetrahedron Letters, 1969, 3665 (1969); E. J. Corey, N. M. Weinshenker, T. K. Schaaf and W. Huber, J. Am. Chem. Soc., 91, 5675 (1969); V. A. Polenov and Yu. A. Zhdanov, Zh. Obsch. Khim., 37, 2456 (1967); Yu. A. Zhdanov and V. A. Polenov, J. Gen. Chem. of U.S. S.R., 1969107 (1969); B. A. Dmitriev and H. K. Kochetkov, Bull. Acad. Sci. of U.S.S.R. (Div. of Chem. Sci.), 1967, 2483.

18) E. Buchta and F. Andree, Chem. Ber., 92, 3111 (1959).

19) T.1. . was conducted on silica gel $\mathrm{GF}_{254}$ (E. Merck, Darmstadt).

20) A mixture of methanol, concentrated sulfuric acid and $p$-methoxybenzaldehyde $(8.5: 1.0: 0.5, \mathrm{v} / \mathrm{v})$.

21) The assignments of other spots were speculated. Spot A might be due to the condensation product of formaldehyde with XX. Spot B corresponded to triphenyl-phosphine oxide. Spot $C$ was observed when only $X X$ was spotted on t.l.c. and so derived from the degradation product of $X X$. Spot $F$ was due to unreacted XVIII.

22) Compounds $\mathrm{D}$ and $\mathrm{E}$ would not be cis, transisomers, because the hydrogenated compounds of D and E gave different spots on t.l. . hemicrystalline product which agreed on t.l.c. with an authentic specimen of $(+)$-desthiobiotin methyl ester prepared by desulfurization of Ib. From these results, D was proved to be the desired compound XIX.

Finally the hemicrystalline reduction-product was hydrolized with a base to afford crystals $\left(\mathrm{mp} 162^{\circ} \mathrm{C},[\alpha]_{\mathrm{D}}+7.00\right.$ ) which showed no depression of the melting point when mixed with an authentic specimen of $(+)$-desthiobiotin. The IR spectrum of the crystals was completely identical with that of the authentic specimen (Fig. 4).

Based on the agreement of the signs of specific rotations between IIa derived from the sugar and an authentic specimen of $(+)$ desthiobiotin $\left([\alpha]_{D}+10.4^{\circ}\right)$, the absolute structure of $(+)$-desthiobiotin was established as 7,8-N-carbonyl-7(R),8(S)-diamino-nonanoic acid (IIa).

This also indicates that desulfurization of Ib does not disturb the configurations of the two amino-groups.

\section{EXPERIMENTAL}

All melting points are uncorrected. Specific rotations: were measured with a Perkin-Elmer 141 Polarimeter in a $1 \mathrm{dm}$ tube. IR spectra were recorded with a Shimadzu IRS-27 Model D spectrometer. NMR. spectra were recorded at $60 \mathrm{MHz}$ with a Japan Electron Optics C-60 spectrometer. Mass spectra were obtained using a JMS-OISG spectrometer. Circular dichloism was measured with a JASCO ORD/UV-5 spectrometer. Column chromatography was performed with silica gel $(0.05 \sim 0.20 \mathrm{~mm}$, E. Merck) and the solvent systems specified.

Methyl 2-O-benzoyl-4,6-O-benzylidene-3-deoxy- $\alpha$-D-ribohexopyranoside $(I I I b)$. Benzoyl chloride ( $1 \mathrm{~g}$ ) was added to a solution of IIIa $(1.3 \mathrm{~g})$ in anhydrons pyridine $(10 \mathrm{ml})$. After the mixture was kept over night at $0^{\circ} \mathrm{C}$ it was poured into ice-water $(c a .150 \mathrm{ml})$ and extracted with chloroform $(150 \mathrm{ml})$. The extract was washed enough successively with cold aqueous sulfuric acid $(29)$, saturated aqueous sodium bicarbonate and water and then dried over anhydrous sodium sulfate. Evaporation in vacuo gave a colorless syrup which solidified soon $(1.75 \mathrm{~g}$, quantitative yield). Recrystal- 
lization from isopropyl ether was conducted as described below. After the crude syrupy IIIb was dissolved in hot isopropyl ether, the solution was evaporated on a hot plate to ca. $20 \mathrm{ml}$ and it was allowed to stand at room temperature to give prisms.

For analyses, a part of III was chromatographed on silica gel in $n$-hexane-ethyl acetate $(6: 1 \mathrm{v} / \mathrm{v})$. mp $121 \sim 123^{\circ} \mathrm{C},[\alpha]_{\mathrm{D}}^{32}+87.6\left(c=4.61, \mathrm{CHCl}_{3}\right), \nu_{\mathrm{max}}^{\mathrm{K} \mathrm{Br}} \mathrm{cm}^{-1}$ : $1710(\mathrm{C}=\mathrm{O}), 1600,1590,1490$ (benzene ring). Anal. Found: $\mathrm{C}, 68.38 ; \mathrm{H}, 6.09$. Calcd, for $\mathrm{C}_{21} \mathrm{H}_{22} \mathrm{O}_{6} \mathrm{C}: \mathrm{C}$, $68.09 ; \mathrm{H}, 5.99 \%$.

Methyl 4-O-benzoyl-6-bromo-3,6-dideoxy- $\alpha-D$-ribo-hexopyranoside $(I V)$. To a suspension of N-bromosuccinimide (181 $\mathrm{mg}$ ) and barium carbonate $(330 \mathrm{mg})$ in carbon tetrachloride $(17 \mathrm{ml})$ was added IIIa $(267 \mathrm{mg})$. The mixture was heated under reflux for $1.5 \mathrm{hr}$ and cooled to $0^{\circ} \mathrm{C}$. After filtration the filtrate was evaporated in vacuo to give a pale yellow syrup which was chromatographed on silica gel in ethyl acetatecyclohexane $(1: 2 \mathrm{v} / \mathrm{v})$; yield $304 \mathrm{mg}(88 \%) . \quad[\alpha]_{\mathrm{D}}^{21}+$ $115^{\circ}\left(c=1.60, \mathrm{CHCl}_{3}\right), \nu_{\mathrm{max}}^{\mathrm{fim}} \mathrm{cm}^{-1}: 3300 \sim 3400(\mathrm{OH})$, $1710(\mathrm{C}=\mathrm{O})$. Anal. Found: C, 48.72; H, 4.92; Br, 22.82. Calcd. for $\mathrm{C}_{14} \mathrm{H}_{17} \mathrm{O}_{5} \mathrm{Br}: \mathrm{C}, 48.69 ; \mathrm{H}, 4.97: \mathrm{Br}$, 23.149.

Methyl 3,6-dideoxy- $\alpha$-b-ribo-hexopyranoside $(V)$. To a suspension of Raney $\mathrm{Ni}$ ( $\mathrm{ca} .2 \mathrm{~g}$ ) in $10 \%$ aqueous potassium hydroxide $(10 \mathrm{ml})$ was added a solution of IV $(2.2 \mathrm{~g})$ in methanol $(35 \mathrm{ml})$. The mixture was shaken in hydrogen for $2 \mathrm{hr}$ at room temperature. After filtration of the catalyst, the filtrate was neutralized with dry ice and evaporated in vacuo to dryness. The resulting residue was extracted with acetone (50 $\mathrm{ml}$ ) and the extract was evaporated in vacuo to give colorless syrupy $\mathrm{V}(900 \mathrm{mg}, 87,0)$, which was partially chromatographed for analyses. $[\alpha]_{D}^{18}+159^{\circ}(c=2.70$, p-dioxane), Anal. Found: C, 51.31; H, 8.72. Calcd. for $\mathrm{C}_{7} \mathrm{H}_{14} \mathrm{O}_{4}: \mathrm{C}, 51.84 ; \mathrm{H}, 8.709$.

Methyl 2-O-benzoyl-3-deoxy- $\alpha-D$-ribo-hexopyranoside (VIa). To a solution of IIIb $(900 \mathrm{mg})$ in $p$-dioxane $(18 \mathrm{ml})$ was added aqueous sulfuric acid $(1.5 \%, 10 \mathrm{ml})$ and the mixture was heated at $55^{\circ} \mathrm{C}$ overnight. After the solution was neutralized at $50^{\circ} \mathrm{C}$ with a large excess of barium carbonate it was filtered and the resulting filtrate was evaporated in vacuo to give amorphous IVa $(600 \mathrm{mg}, 87 \%)$, which was dissolved in a mixture of isopropyl ether and acetone (ca. $3: 1$ ) and subsequently evaporated to $1 / 3 \sim 1 / 4$ volume on a hot plate to afford crystalline IVa. mp $131 \sim 133^{\circ} \mathrm{C}$,
$[\alpha]_{\mathrm{D}}^{25}+101^{\circ}\left(c=3.31, \mathrm{CHCl}_{3}\right), \nu_{\max }^{\mathrm{KBr}} \mathrm{cm}^{-1}: 3250(\mathrm{OH})$, $1725(\mathrm{C}=\mathrm{O})$. Anal. Found: $\mathrm{C}, 59.50 ; \mathrm{H}, 6.39$. Calcd. for $\mathrm{C}_{14} \mathrm{H}_{18} \mathrm{O}_{6}: \mathrm{C}, 59.56 ; \mathrm{H}, 6.43 \%$.

Methyl 2-O-benzoyl-3-deoxy-6-O-tosyl- $\alpha-\nu-r i b o-h e x-$ opyranoside (VIb). A solution of VIa (1.4 g) in dry pyridine $(15 \mathrm{ml})$ was cooled in an ice-salt bath. To the solution was added $p$-tolylsulfonyl chloride $(1.15 \mathrm{~g}$ ) and the mixture was kept at $-5 \mathrm{C}$ for 6 days. After the mixture was poured into ice-water it was extracted with chloroform $(150 \mathrm{ml})$. The extract was washed successively with aqueous sulfuric acid (3\%), aqueous sodium bicarbonate and water and then dried over anhydrous sodium sulfate. It was evaporated in vacuo to afford syrupy VIb contaminated with a trace of 4,6-ditosylate.

The product was chromatographed on silica gel $(150 \mathrm{~g})$ in benzene-ether $(8: 1 \rightarrow 4: 1 \mathrm{v} / \mathrm{v})$ to give pure VIb $(1.5 \mathrm{~g}, 698)$ which resisted to crystallization. $[\alpha]_{\mathrm{D}}^{22}+58.1 \quad\left(c=2.61, \mathrm{CHCl}_{3}\right), \nu_{\mathrm{maX}}^{\mathrm{fllm}} \mathrm{cm}^{-1}: 1180,1360$ $\left(\mathrm{SO}_{2}\right), 1720(\mathrm{C}=\mathrm{O}) 3500(\mathrm{OH})$. Anal. Found: $\mathrm{C}, 58.28$ $\mathrm{H}, 5.53 ; \mathrm{S}, 7.17$. Calcd. for $\mathrm{C}_{21} \mathrm{H}_{24} \mathrm{O}_{8} \mathrm{~S}: \mathrm{C}, 57.79 ; \mathrm{H}$, $5.54 ; \mathrm{S}, 7.35 \%$.

Methyl 2-O-benzoyl-3,6-dideoxy-6-iodo-a-D-ribo-hexopyranoside $(V I I)$. A solution of VIb $(1.4 \mathrm{~g})$ and sodium iodide $(1.5 \mathrm{~g})$ in 2-butanone was heated under reflux for $6 \mathrm{hr}$ and cooled. The precipitate was filtered off and the filtrate was evaporated in vacuo to dryness. After the residue was extracted with chloroform $(50 \mathrm{ml})$, the extract was washed with water, dried over anhydrous sodium sulfate and evaporated in vacuo to give a solid mass (VII, $1.3 \mathrm{~g}, 104 \%$ ). Recrystallization from a mixture of ethyl acetate and $n$-hexane gave colorless needles. $\mathrm{mp} 131 \sim 132^{\circ} \mathrm{C},[\alpha]_{\mathrm{D}}^{20}+70.5\left(c=2.66, \mathrm{CHCl}_{3}\right)$, $\nu_{\max }^{\mathrm{KBr}} \mathrm{cm}^{-1}: 1700(\mathrm{C}=\mathrm{O}), 3480(\mathrm{OH})$. Anal. Found: $\mathrm{C}$, $42.82 ; \mathrm{H}, 4.43 ; \mathrm{I}, 32.51$. Calcd. for $\mathrm{C}_{14} \mathrm{H}_{17} \mathrm{O}_{5} \mathrm{I}: \mathrm{C}$, $42.87 ; \mathrm{H}, 4.37 ; \mathrm{I}, 32.36 \%$.

Methyl 2-O-benzoyl-3,6-dideoxy- $\alpha$-D-ribo-hexopyranoside (VIIIa). To a solution of VII ( $7 \mathrm{~g})$ in methanol $(200$ $\mathrm{ml})$ were added a solution of sodium acetate trihydrate $(5 \mathrm{~g})$ in water $(20 \mathrm{ml})$ and palladium on carbon $(10 \%$, $c a .1 \mathrm{~g}$ ). The mixture was shaken in hydrogen until the absorption of the gas stopped.

After filtration of the catalyst aqueous sodium bicarbonate (saturated, $30 \mathrm{ml}$ ) was added to the filtrate and the mixture was evaporated in vacuo to dryness. The resulting residue was extracted with chloroform and the extract was washed with water, dried over anhydrous sodium sulfate and evaporated in vacuo to 
give syrupy VIIIa $(3.6 \mathrm{~g}, 76 \%)$ which revealed one spot on t.l.c. (benzene-ether, $4: 1 \mathrm{v} / \mathrm{v}$ ). For analyses, a part of VIIIa was chromatographed on silica gel in benzene-ether $(6: 1 \mathrm{v} / \mathrm{v}) . \quad[\alpha]_{\mathrm{D}}^{20}+96.4^{\circ} \quad(c=1.96$, $\mathrm{CHCl}_{3}$ ). Anal. Found: C, 63.13; H, 6.57. Calcd. for $\mathrm{C}_{14} \mathrm{H}_{18} \mathrm{O}_{5}: \mathrm{C}, 63.14 ; \mathrm{H}, 6.81 \%$.

Methyl 2-O-benzayl-3,6-dideoxy-4-O-mesyl- $\alpha$-D-ribo-hexopyranoside (VIIIb). Methylsulfonyl chloride (2 g) was added under cooling with ice to a solution of VIa $(2.3 \mathrm{~g})$. The mixture was kept over night at $5^{\circ} \mathrm{C}$ and poured into ice-water $(c a .100 \mathrm{ml})$ to yield a precipitate (VIIIb) which was filtered off, washed with water, dried, and recrystallized from isopropyl ether $(2.8 \mathrm{~g}$, $94 \%)$. mp $100 \sim 103^{\circ} \mathrm{C},[\alpha]_{\mathrm{D}}^{2 \mathrm{l}}+129.0^{\circ}\left(c=1.64, \mathrm{CHCl}_{3}\right)$, ${ }_{2} \mathrm{KBx}_{\max } \mathrm{cm}^{-1}: 1180,1360\left(\mathrm{SO}_{2}\right), 1730(\mathrm{C}=\mathrm{O}), \tau^{23)}: 8.66$ (3-proton, doublet, $J_{5,6} 6 \mathrm{cps}, \mathrm{H}-6$ ), 6.18 (1 proton, multiplet which collapsed to a doublet on irradiation at $\left.-8.66, J_{4,5}=10.2 \mathrm{cps}, \mathrm{H}-5\right)$. Anal. Found: C, 52.63; $\mathrm{H}, 5.84 ; \mathrm{S}, 9.24$. Calcd. for $\mathrm{C}_{15} \mathrm{H}_{20} \mathrm{O}_{7} \mathrm{~S}: \mathrm{C}$, $52.31 ; \mathrm{H}, 5.85 ; \mathrm{S}, 9.310_{0}$.

Methyl 4-azido-2-O-benzoyl-3,4,6-trideoxy- $\alpha-1-x y l o-h e x o-$ pyranoside $(I X a)$. To a solution of VIIIb $(2.5 \mathrm{~g})$ in DMF $(80 \mathrm{ml})$ was added a solution of sodium azide $(2 \mathrm{~g})$ and urea $(400 \mathrm{mg})$ in water $(6 \mathrm{ml})$. The mixture was heated at $120^{\circ} \mathrm{C}$ for $7 \mathrm{hr}$, poured into water $(300$ $\mathrm{ml})$ and extracted with ether $(500 \mathrm{ml})$. After washing with water the extract was dried over sodium sulfate and evaporated in vacuo to give syrupy VIIa $(2.0 \mathrm{~g}$, $93 \%$ ), which was chromatographed on silica gel (120 g) in benzene-ether $(12: 1 \mathrm{v} / \mathrm{v})$. The purified IXa crystallized on standing. $\mathrm{mp} 80 \sim 83^{\circ} \mathrm{C}, \quad[\alpha]_{\mathrm{D}}^{21}+61.2^{\circ}$ $\left(c=2.27, \mathrm{CHCl}_{3}\right), \nu_{\max }^{\mathrm{K} \mathrm{Br}} \mathrm{cm}^{-1}: 1720(\mathrm{C}=\mathrm{O}) ; 2100\left(\mathrm{~N}_{3}\right)$, $\tau^{23)}: 8.70$ (3 protons, doublet, $\mathrm{H}-6, J_{5,6} 6.6 \mathrm{~Hz}$ ), 6.26 (1 proton, broad multiplet, $\mathrm{H}-4$ ), 5.90 (1 proton, octet which collapsed to a doublet on irradiation at 58.70 , H-5, $J_{4,5} 1.8 \mathrm{~Hz}$ ). Anal. Found: C, 57.48; H, 5.69; $\mathrm{N}, 14.65$. Calcd. for $\mathrm{C}_{14} \mathrm{H}_{17} \mathrm{O}_{4} \mathrm{~N}_{3}: \mathrm{C}, 57.72 ; \mathrm{H}, 5.88$; $\mathrm{N}, 14.43 \%$. In another run, VIIIb $(51 \mathrm{~g})$ in DMF (1 liter) was treated in a similar way. In this case IXa crystallized as soon as the reaction mixture was poured into water. It could be recrystallized from cyclohexane. $\mathrm{mp} 80 \sim 83^{\circ} \mathrm{C}$.

Methyl 4-azido-3,4,6-trideoxy- $\alpha-D-x y l o-$ hexopyranoside $(I X b)$. An aqueous solution of sodium hydroxide (196,

23) Chloroform-d and tetramethylsilane (TMS) were used as a solvent and as an internal reference, respectively.
$14 \mathrm{ml}$ ) was added to a solution of IXa $(800 \mathrm{mg})$ in ethanol $(30 \mathrm{ml})$. After the mixture was heated at $60^{\circ} \mathrm{C}$ for $1 \mathrm{hr}$, it was neutralized with solid carbon dioxide and evaporated to dryness. The resulting residue was extracted with chloroform $(60 \mathrm{ml})$ and the extract was washed with water, dried over sodium sulfate and evaporated in vacuo to give syrupy IXb which solidified soon. Recrystallization from various solvents was unsuccessful, and IXb was purified by column chromatography on silica gel (cyclohexaneethyl acetate, $2: 1 \mathrm{v} / \mathrm{v})$. $\quad \operatorname{mp} 64 \sim 5^{\circ} \mathrm{C},[\alpha]_{\mathrm{D}}^{23}+107.1^{\circ}$ $\left(c=4.46, \mathrm{CHCl}_{3}\right), \nu_{\max }^{\mathrm{KBr}} \mathrm{cm}^{-1}: 2100\left(\mathrm{~N}_{3}\right), 3450(\mathrm{OH})$, $[\theta]_{286}+188(c=0.0465$, ethanol). Anal. Found: C, 44.77; $\mathrm{H}, 6.94 ; \mathrm{N}, 22.62$. Calcd. for $\mathrm{C}_{7} \mathrm{H}_{13} \mathrm{O}_{3} \mathrm{~N}_{3}: \mathrm{C}, 44.91$; $\mathrm{H}, 7.00 ; \mathrm{N}, 22.45 \%$. This compound sublimes under reduced pressure.

4-Azido-3,4,6-trideoxy- $\alpha-D-x y l o-h e x o p y r a n o s e ~(X)$. Sulfuric acid $(98 \%, 0.3 \mathrm{ml})$ was added dropwise to a solution of IXa $(1.8 \mathrm{~g})$ in acetic anhydride $(30 \mathrm{ml})$ under cooling in an ice-both. The mixture was allowed to stand at room temperature for 5 days. The solution was poured into ice-water $(250 \mathrm{ml})$, neutralized with an excess of sodium bicarbonate and extracted with dichloromethane $(300 \mathrm{ml})$. The extract was washed with water, dried over sodium sulfate, and evaporated in vacuo to afford a brown syrup $(1.73 \mathrm{~g}$ ), which showed two main spots ${ }^{24}$ and two faint spots on t.l.c. (silica gel G. benzene-ether $8: 1 \mathrm{v} / \mathrm{v}$ ). Two major products (anomers of I-acetate) were isolated in whole by column chromatography by using silica gel $(100 \mathrm{~g})$ and benzene-ether $(10: 1 \mathrm{v} / \mathrm{v})$ as an eluent; yield $1.1 \mathrm{~g}(55 \%), \nu_{\max }^{\operatorname{6lm}} \mathrm{cm}^{-1}: 1490,1500,1590,1605$ (benzene ring), $1720 \sim 1770\left(\mathrm{C}=\mathrm{O}\right.$ of esters), $2100\left(\mathrm{~N}_{3}\right)$.

The anomeric mixture of 1 -acetate $(1.1 \mathrm{~g})$ was dissolved in methanol $(25 \mathrm{ml})$ and cooled in an ice-bath. Aqueous sodium hydroxide $(1 \mathrm{~N}, 6.8 \mathrm{ml})$ was added to the solution and the mixture was kept for $2 \mathrm{hr}$ at $0^{\circ} \mathrm{C}$. After neutralization with solid carbon dioxide the mixture was evaporated in vacuo below $45^{\circ} \mathrm{C}$ and the resulting residue was extracted with acetone $(30 \mathrm{ml})$. The extract was evaporated in vacuo to afford a yellow syrup, which was kept at $0^{\circ} \mathrm{C}$, allowed to crystallize overnight and recrystallized from isopropyl ether-acetone; yield $540 \mathrm{mg}$ (90,0 from 1 acetate). $\operatorname{mp} 87 \sim 90^{\circ} \mathrm{C},[\alpha]_{\mathrm{D}}^{20}-14.5^{\circ}(6 \mathrm{~min}) \rightarrow-43.4^{\circ}$ $\left(66 \mathrm{~min}\right.$, const.) $\left(c=1.43, \mathrm{H}_{2} \mathrm{O}\right), \nu_{\mathrm{max}}^{\mathrm{KBr}} \mathrm{cm}^{-1}: 2100\left(\mathrm{~N}_{3}\right)$, $3300 \sim 3500(\mathrm{OH}), \tau^{25)}: 8.89$ (three protons, doublet,

24) They moved so close to each other. 
$\mathrm{H}-6, J_{5,6} 6.6 \mathrm{~Hz}$ ), 5.90 (1 proton, quartet, H-5, $J_{4,5}$ $1.8 \mathrm{~Hz} ; J_{5,6} 6.6 \mathrm{~Hz}$ ), 5.41 (1 proton, doublet which disappeared on addition of $\mathrm{D}_{2} \mathrm{O}, \mathrm{OH}-2, J_{2, \mathrm{OH}} 7.2 \mathrm{~Hz}$ ), 5.12 ( 1 proton, quartet which collapsed to a doublet on irradiation at $\tau 3.67, \mathrm{H}-1, J_{1, \mathrm{OH}} 4.2 \mathrm{~Hz}, J_{1,2} 3.6$ $\mathrm{Hz}$ ), 3.67 (1 proton, doublet which collapsed to a singlet on irradiation at $\tau 5.12, \mathrm{OH}-1, J_{1, \mathrm{OH}} 4.2 \mathrm{~Hz}$ ). Anal. Found: C, 41.70; H, 6.23; N, 24.29. Calcd. for $\mathrm{C}_{6} \mathrm{H}_{11} \mathrm{O}_{3} \mathrm{~N}_{3}: \mathrm{C}, 41.61 ; \mathrm{H}, 6.40 ; \mathrm{N}, 24.270$ '.

4-Azido-3,4,6-trideoxy- $\alpha-D$-xylo-hexopyranose p-tolylsulfonylhydrazone $(X I)$. A solution of $X(96 \mathrm{mg})$ and $p$ tolylsulfonylhydrazide $(113 \mathrm{mg}$ ) in methanol $(3 \mathrm{ml})$ was heated under reflux for $1 \mathrm{hr}$. Although several products were detected on t.l.c. (silica gel $\mathrm{G}, \mathrm{CHCl}_{3}$ $\mathrm{CH}_{3} \mathrm{OH}, 94: 6 \mathrm{v} / \mathrm{v}$ ), XI crystallized from the mixture on standing in an open flask for 2 days. The crude $\mathrm{XI}$ was recrystallized from ethanol. Yield $68 \mathrm{mg}$ (35\%). $\mathrm{mp} 146^{\circ} \mathrm{C}$ (Decompose), $[\alpha]_{\mathrm{D}}^{22}-54.0^{\circ} \quad(5 \mathrm{~min}$, $c=1.30$, p-dioxane). Anal. Found: C, 45.96; H, 5.83; $\mathrm{N}, 20.70 ; \mathrm{S}, 9.37$. Calcd. for $\mathrm{C}_{13} \mathrm{H}_{19} \mathrm{O}_{4} \mathrm{~N}_{5} \mathrm{~S}: \mathrm{C}, 45.73$; $\mathrm{H}, 5.61 ; \mathrm{N}, 20.51$; S, 9.39\%.

4-Azido-3,4,6-trideoxy-D-xylo-hexitol (XIII). Sodium borohydride (58 $\mathrm{mg}$ ) was added under ice-cooling to a solution of $\mathrm{X}(470 \mathrm{mg})$ in methanol $(3.5 \mathrm{ml})$. The mixture was kept at $0^{\circ} \mathrm{C}$ for $30 \mathrm{~min}$ and then stirred with Amberlite IR-120 $\left(\mathrm{H}^{+}, 1.5 \mathrm{ml}\right)$. After filtration the filtrate was evaporated in vacuo with several additions of methanol and finally to dryness, to give syrupy XII $(540 \mathrm{mg}, 93 \%)$ which showed one spot on t.l.c. (silica gel $\mathrm{G}, \mathrm{CHCl}_{3}-\mathrm{CH}_{3} \mathrm{OH}, 4: 1 \mathrm{v} / \mathrm{v}$ ). For analyses, it was partially chromatographed on silica gel in chloroform-methanol $(9: 1 \mathrm{v} / \mathrm{v}) . \quad[\alpha]_{\mathrm{D}}^{22}+49.0^{\circ}$ $\left(c=2.57, p\right.$-dioxane) $\nu_{\max }^{\mathrm{fi} 1 \mathrm{~m}} c \mathrm{~m}^{-1}: 2150\left(\mathrm{~N}_{3}\right), 3300 \sim 3600$ $(\mathrm{OH})$. Anal. Found: C, 40.59; H, 7.24; N, 23.92 . Calcd. for $\mathrm{C}_{6} \mathrm{H}_{13} \mathrm{O}_{3} \mathrm{~N}_{3}: \mathrm{C}, 41.13 ; \mathrm{H}, 7.48 ; \mathrm{N}, 23.99 \%$.

4-Azido-1,2-0-isopropylidene-3,4,6-trideoxy-D-xylo-hexitol (XIIIa). A mixture of XII ( $500 \mathrm{mg}$ ) and Dowex $50 \mathrm{~W}$ $\left(\mathrm{H}^{+}, 400 \mathrm{mg}\right)$ in dry acetone $(20 \mathrm{ml})$ was stirred for $4 \mathrm{hr}$ at room temperature. After filtration the filtrate was evaporated in vacuo to give syrupy XIIIa, which was chromatographed on silica gel (ethyl acetatecyclohexane, $1: 1 \mathrm{v} / \mathrm{v}$ ); yield $440 \mathrm{mg}(71,0) .[\alpha]_{\mathrm{D}}^{22}+$ $27.7^{\circ}\left(c=1.52, \mathrm{CHCl}_{3}\right) \nu_{\max }^{\mathrm{KBr}} \mathrm{cm}^{-1}: 2150\left(\mathrm{~N}_{3}\right)$. Anal.

25) Dimethylsulfoxide-d $\mathrm{d}_{6}$ and sodium 2,2-dimethyl2-silapentane-5-sulfonate (DSS) were used as a solvent and as an internal standard, respectively.
Found: $\mathrm{C}, 50.14 ; \mathrm{H}, 8.02 ; \mathrm{N}, 19.54$. Calcd. for $\mathrm{C}_{9} \mathrm{H}_{17} \mathrm{O}_{3} \mathrm{~N}_{3}: \mathrm{C}, 50.22 ; \mathrm{H}, 7.96 ; \mathrm{N}, 19.52 \%$.

4-Azido-1, 2-O-isopropylidene-5-O-methylsulfonyl-3, 4, 6trideoxy-D-xylo-hexitol (XIIIb). Methylsulfonyl chloride (300 mg) was added under cooling to a solution of XIIla $(280 \mathrm{mg})$ in pyridine $(3 \mathrm{ml})$. After the mixture was kept at $0^{\circ} \mathrm{C}$ overnight, it was poured into icewater and extracted with chloroform $(30 \mathrm{ml})$. The extract was washed with cold aqueous sulfuric acid (below 30) and water, dried over anhydous sodium sulfate and evaporated in vacuo to give syrupy XIIIb ( $320 \mathrm{mg}, 83 \%$ ). For analyses, it was chromatographed on silica gel (cyclohexane-ethyl acetate, $3: 1 \mathrm{v} / \mathrm{v}$ ). $[\alpha]_{\mathrm{D}}^{26}+72.6\left(c=1.72, \mathrm{CHCl}_{3}\right), \nu_{\max }^{\mathrm{fim}} \mathrm{cm}^{-1}: \quad 1175,1360$ $\left(\mathrm{SO}_{2}\right), 2100\left(\mathrm{~N}_{3}\right)$. Anal. Found: C, 40.99; H, 6.53; $\mathrm{N}, 14.37 ; \mathrm{S}, 10.96$. Calcd. for $\mathrm{C}_{10} \mathrm{H}_{19} \mathrm{O}_{5} \mathrm{~N}_{3} \mathrm{~S}: \mathrm{C}, 40.95$; $\mathrm{H}, 6.53 ; \mathrm{N}, 14.32 ; \mathrm{S}, 10.93 \%$.

4, 5-Diazido-1, 2-O-isopropylidene-3, 4, 5, 6-tetradeoxy-Larabino-hexitol $(X I V)$. To a solution of XIIIb $(2.9 \mathrm{~g})$ in DMF $(100 \mathrm{ml})$ was added a solution of sodium azide $(2 \mathrm{~g})$ and urea $(400 \mathrm{mg})$ in water $(10 \mathrm{ml})$. The mixture was heated at $110^{\circ} \mathrm{C}$ overnight and evaporated in vacuo. To the resulting residue were added chloroform $(150 \mathrm{ml})$ and water $(100 \mathrm{ml})$. The chloroform layer was separated, washed with water $(50 \mathrm{ml})$, dried over sodium sulfate and evaporated in vacuo to afford syrupy XIV, which was chromatographed on silica gel (cyclohexane-ethyl acetate, $7: 1 \mathrm{v} / \mathrm{v}$ ); yield $2.2 \mathrm{~g}$ $(92,0) .[\alpha]_{\mathrm{D}}^{23}+126.7\left(c=1.16, \mathrm{CHCl}_{3}\right), \nu_{\mathrm{max}}^{\mathrm{flm}} \mathrm{cm}^{-1}: 2100$ $\left(\mathrm{N}_{3}\right), m / e: 225\left(\mathrm{M}^{+}-\mathrm{CH}_{3}\right)$. Anal. Found: $\mathrm{C}, 45.03 ; \mathrm{H}$, 6.72; N, 34.84. Calcd. for $\mathrm{C}_{9} \mathrm{H}_{16} \mathrm{O}_{2} \mathrm{~N}_{6}: \mathrm{C}, 44.99 ; \mathrm{H}$, $6.71 ; \mathrm{N}, 34.98 \%$.

4, 5-Diamino-1, 2-O-isopropylidene-3, 4, 5, 6-tetradeoxy- $x$ arabino-hexitol $(X V)$. To a solution of XIV $(800 \mathrm{mg})$ in methanol $(25 \mathrm{ml})$ was added Raney $\mathrm{Ni}$ and the mixture was shaken in hydrogen under a pressure $\left(4 \mathrm{~kg} / \mathrm{cm}^{2}\right)$ at room temperature for $3 \mathrm{hr}$. After filtration of the catalyst the filtrate was evaporated in vacuo to yield syrupy XV (400 mg, 63\%), which was then used for the preparation of XVI without further purification.

The crude $\mathrm{XV}$ gave a positive result in the ninhydrin test and had no absorption at $2100 \sim 2200\left(\mathrm{~N}_{3}\right)$ in the IR spectrum.

4,5-N-Carbonyl-4,5-diamino-1,2-O-isopropylidene-3,4,5,6tetradeoxy-L-arabino-hexitol (XVI). Carbonyl chloride was bubbled for $50 \mathrm{~min}$ at room temperature into a 
solution of XV (200 mg) in aqueous sodium carbonate $(10 \%, 20 \mathrm{ml})$. A drop of methanolic phenolphthalein was added every ten minutes during the reaction in order to make sure that the solution was kept alkaline. The mixture was evaporated in vacuo to $1 / 4$ volume and extracted with chloroform $(150 \mathrm{ml})$. The extract was dried over sodium sulfate and evaporated in vacuo to give syrupy XVI (120 mg, 53\%) which crystallized soon. It was recrystallized from ethylacetate- $n$-hexane. $\operatorname{mp~} 128 \sim 129^{\circ} \mathrm{C},[\alpha]_{\mathrm{D}}^{34}+32.9^{\circ}(c=$ $\left.1.04, \mathrm{CHCl}_{3}\right) \nu_{\max }^{\mathrm{KBr}} \mathrm{cm}^{-1}: 1710(\mathrm{C}=\mathrm{O}) .3250(\mathrm{NH}), m / e$ : $214\left(\mathrm{M}^{+}\right), 199\left(\mathrm{M}^{+}-\mathrm{CH}_{3}\right)$. Anal. Found: C, 56.29; H, 8.27; N, 13.27. Calcd. for $\mathrm{C}_{10} \mathrm{H}_{18} \mathrm{O}_{3} \mathrm{~N}_{2}: \mathrm{C}$, 56.05; $\mathrm{H}, 8.47 ; \mathrm{N}, 13.08 \%$.

4,5-N-Carbonyl-4,5-diamino-3,4,5,6-tetradeoxy-L-arabinohexitol (XVII). A mixture of XVI $(230 \mathrm{mg})$ and Dowex $30 \mathrm{~W}\left(\mathrm{H}^{+}, 240 \mathrm{mg}\right)$ was stirred in water $(12 \mathrm{ml})$ for $1 \mathrm{hr}$ at room temperature.

After filtration the filtrate was evaporated in vacuo to afford cyrstallive XVII (160 mg, 86\%), which was recrystallized from a small amount of methanol. $\mathrm{mp} 125 \sim 130^{\circ} \mathrm{C}, \quad[\alpha]_{\mathrm{D}}^{z u}+43.9^{\circ} \quad(c=2.55$, ethanol $)$, $\nu_{\max }^{\mathrm{K} \mathrm{Br}} \mathrm{cm}^{-1}: 1660,1680$ (shoulder) $(\mathrm{C}=\mathrm{O}), 3300,3400$ ( $\mathrm{OH}$ and $\mathrm{NH}$ ). Anal. Found: $\mathrm{C}, 48.66 ; \mathrm{H}, 7.86 ; \mathrm{N}$, 16.00. Calcd from $\mathrm{C}_{7} \mathrm{H}_{14} \mathrm{O}_{3} \mathrm{~N}_{2}: \mathrm{C}, 48.26 ; \mathrm{H}, 8.10$; $\mathrm{N}, 16.08 \%$.

Sodium periodate oxidation of $X V I I$ and the subsequent Wittig reaction to methyl 7,8-N-carbonyl-7(R), $8(S)$ diamino-nona-2,4-dienoate $(X I X)$. Sodium periodate (792 $\mathrm{mg}$ ) was added to a cold solution of XVII (580 $\mathrm{mg}$ ) in water $(20 \mathrm{ml})$. After the mixture was kept for $2 \mathrm{hr}$ at $0^{\circ} \mathrm{C}$, it was evaporated completely by freeze-drying and extracted with absolute ethanol $(90 \mathrm{ml})$.

Wittig reagent $(\mathrm{XX}, 2.4 \mathrm{~g})$ was added to the extract and the mixtue was stirred for two days at room temperature, protecting from a moisture. The resulting solution was evaporated in vacuo to dryness and the residue was suspended in ethyl acetate $(30 \mathrm{ml})$. After removal of an impurity by filtration the filtrate was evaporated to a volume of ca. $20 \mathrm{ml}$ and the resulting triphenylphosphine oxide $(800 \mathrm{mg})$ was filtered off.

The filtrate was evaporated and chromatographed on silica gel $\left(130 \mathrm{~g}, \mathrm{CHCl}_{3}-\mathrm{CH}_{3} \mathrm{OH}, 94: 6 \mathrm{v} / \mathrm{v}\right)$. The fractions containing $\mathrm{D}$ and $\mathrm{E}$ (Fig. 3 ) were collected and evaporated to afford a deeply brown syrup (200 $\mathrm{mg}$ ), from which components $\mathrm{D}$ and $\mathrm{E}$ were isolated respectively by twice repeated preparative layer chromatography (silica gel $\mathrm{GF}_{254}, 2 \mathrm{~mm}$ thick, $20 \mathrm{~cm} \times$ $20 \mathrm{~cm}, \mathrm{CHCl}_{3}-\mathrm{CH}_{3} \mathrm{OH} 94: 6 \mathrm{v} / \mathrm{v}$, detected by $\mathrm{UV}$ light). Almost pure D (XIX, $70 \mathrm{mg}$ ) and crude $\mathrm{E}$ (25 mg) were obtained.

(+)-Desthiobiotin (IIa) via its methyl ester (IIb). A solution of XIX $(63 \mathrm{mg})$ in methanol was shaken at room temperature in hydrogen with Adams catalyst, absorbing $11 \mathrm{ml}$ of hydrogen. After filtration the filtrate was evaporated in vacuo to give a syrup, which was distilled at $100 \sim 110^{\circ} \mathrm{C}$ under a high vacuum $\left(2 \times 10^{-5} \mathrm{mmHg}\right)$. As the distillate was found to be contaminated with a trace of impurity according to t.l.c., it was chromatographed on silica gel $(7 \mathrm{~g})$ in chloroform-methanol $(96: 4 \mathrm{v} / \mathrm{v})$. The resulting syrup (36 mg) crystallized ${ }^{26)}$ on standing and was identical with an authentic specimen of $\mathrm{Ib}$ on t.l.c. ${ }^{27}$ ) (silica gel $\mathrm{G}, \mathrm{CHCl}_{3}-\mathrm{CH}_{3} \mathrm{OH}, 9: 1 \mathrm{v} / \mathrm{v}$ ). To a solution of the crystals $(36 \mathrm{mg})$ in ethanol $(0.025 \mathrm{ml})$ was added a solution of aqueous sodium hydroxide $(1 \mathrm{~N}, 0.25 \mathrm{ml})$. After the mixture was kept at $50^{\circ} \mathrm{C}$ for $30 \mathrm{~min}$, it was acidified with aqueous hydrogen chloride $(5 \mathrm{~N}$, $0.05 \mathrm{ml}$ ) to afford crystalline $\mathrm{Ia}$, which was filtered off, washed with water and dried; yield $20 \mathrm{mg}(6 \%$ for XVII). $m p 160 \sim 162^{\circ} \mathrm{C}$. No depression when mixed with an authentic specimen. $\left[x\left[\left[_{D}^{19}+7.00(c=\right.\right.\right.$ 0.91 , ethanol). ${ }^{281}$

Its IR spectrum completely agreed with that of an authentic sample (Fig. 4).

Acknowledgement. The authors wish to express their thanks to Dr. H. Homma and his colaborators for elemental analyses. The authors are also grateful to Mr. J. Uzawa and his co-workers for measurement of NMR spectra and to Mr. H. Terayama for preparation of the starting material.

26) The melting point was too low to observe.

27) Detected by spraying with $10 \%$ aqueous sulfuric acid and charring.

28) $[\alpha]_{\mathrm{D}}^{17}+10.4(c=0.58$, ethanol $)$ for the authentic sample. 